\title{
Erratum to: Enhancement of PR1 and PR5 gene expressions by chitosan treatment in kiwifruit plants inoculated with Pseudomonas syringae pv. actinidiae
}

\author{
B. Corsi • C. Forni • L. Riccioni • J. M. H. Linthorst
}

Published online: 6 December 2016

(C) Koninklijke Nederlandse Planteziektenkundige Vereniging 2016

\section{Erratum to: Eur J Plant Pathol DOI 10.1007/s10658-016-1080-x}

Author names / surnames interchanged and needs to be corrected.

\section{B. Corsi. C. Forni}

Department of Biology, University of Rome BTor Vergata $^{\wedge}$, Via della Ricerca Scientifica, 00133 Rome, Italy
B. Corsi. L. Riccioni (*)

Consiglio per la ricerca in agricoltura e l'analisi dell'economia agraria, Centro di Ricerca per la Patologia Vegetale (CREA-PAV), Via C.G. Bertero, 00156 Rome, Italy

J. M. H. Linthorst

Institute of Biology, Leiden University, Sylvius Laboratory, Sylviusweg, 72, 2333 Leiden, The Netherlands

The online version of the original article can be found at http://dx. doi.org/10.1007/s10658-016-1080-x

B. Corsi $\cdot$ C. Forni

Department of Biology, University of Rome BTor Vergata, Via della Ricerca Scientifica, 00133 Rome, Italy

B. Corsi $\cdot$ L. Riccioni $(\bowtie)$

Consiglio per la ricerca in agricoltura e l'analisi dell'economia agraria, Centro di Ricerca per la Patologia Vegetale (CREA-PAV), Via C.G. Bertero, 00156 Rome, Italy e-mail: luca.riccioni@crea.gov.it

J. M. H. Linthorst Institute of Biology, Leiden University, Sylvius Laboratory, Sylviusweg, 72, 2333 Leiden, The Netherlands 